\title{
Analysis of Calculation Errors for Single-zone and Multi-Zone Natural Ventilation model in Residential Building
}

\author{
Zheqi Xuan ${ }^{1, *}$, Xiaohong Zheng ${ }^{1}$, Zhenni Shi $^{1}$ \\ ${ }^{1}$ School of Energy and Environment, Southeast University, Nanjing, 210096, China
}

\begin{abstract}
The typical residential building in Changzhou City, Jiangsu Province was selected for natural ventilation measurement during the transitional season, the plum rainy season, summer and winter. In this paper, $\mathrm{SF}_{6}$ is used as the tracer gas, and tracer gas decay method was selected to obtain the air change rate in the room under each measuring condition. EnergyPlus(EP) was used to calculate the single-zone and multizone air change rate which can be compared with the measured values respectively. It was found that the calculated values of single-zone model were generally small and the errors were large. And the calculated values of multi-zone model have a significant reduction in error after considering the equivalent infiltration area. In addition, the effective infiltration area will be different due to the existence of the thermal expansion coefficient for different seasons.
\end{abstract}

\section{Introduction}

Residential buildings mainly rely on infiltration and natural ventilation to achieve ventilation. The natural ventilation of the buildings is mainly through the ventilation of the building envelope and other purposeful ventilation. Statistical survey results show that $86.8 \%$ of typical residential residents in northern China chose single-sided ventilation[1]. When the doors and windows are closed, the air change rate in residential building is between $0.02 \sim 0.8 \mathrm{~h}^{-1}[2]$. The energy consumption caused by infiltration reaches $10.5 \% \sim 27.4 \%$ of the total building energy consumption[3].

EnergyPlus (EP) is commonly used as the energy consumption simulation software. The natural ventilation module contains empirical model and multi-zone model. It integrates multiple models used in ventilation simulation software such as COMTAM and COMIS.

In this paper, the values of single-zone and multi-zone air change rate in residential buildings are calculated by EnergyPlus(EP). Compare the calculated values with measured values by combing the thermal expansion coefficient.

\section{Method}

\subsection{Field Measurement}

\subsubsection{Measurement methods}

Tracer gas decay method is widely used to measure the room air change rate. The method is based on the principle of mass conservation. And the air change rate of the room is obtained by the change of the tracer gas concentration in the room[4]. Tracer gas mass conservation equation is as shown in equation( 1 .

$$
\left\{\begin{array}{l}
\frac{d C_{i n, \tau}}{d \tau}=n\left(\mathrm{C}_{o u t}-\mathrm{C}_{i n}\right)+\frac{E}{V} \\
C_{i n, \tau}=C_{i n, 0}, \tau=0
\end{array}\right.
$$

where $\tau$ is time; $C_{i n, \tau}$ is the concentration of indoor tracer gas at time $\tau ; C_{i n, 0}$ is the concentration of indoor tracer gas at time $0 ; C_{\text {out }}$ is the concentration of outdoor tracer gas; $V$ is the room volume; $n$ is the room air change rate; $E$ is tracer gas emission rate.

During the measurement, the tracer gas emission rate is 0 . The nonlinear regression equation can be obtained from equation (1):

$$
C_{i n, \tau}=\left(\mathrm{C}_{i n, 0}-\mathrm{C}_{\text {out }}\right) \exp (-n \tau)+\mathrm{C}_{\text {out }}
$$

Take the logarithm of equation (2) to get its linear regression equation:

$$
\ln \left(\frac{\mathrm{C}_{\text {in }, 0}-\mathrm{C}_{\text {out }}}{\mathrm{C}_{\text {in }, \tau}-\mathrm{C}_{\text {out }}}\right)=n \tau+b
$$

where $b$ is the fitting intercept of linear regression equation.

$\mathrm{SF}_{6}$ was selected as tracer gas in the measurement. The background concentration of $\mathrm{SF}_{6}$ in air is 0 [5].

\subsubsection{Measurement arrangement}

The building under measurement is located in Changzhou, Jiangsu Province. It consists of a bedroom, a living room, a kitchen and a bathroom. It simulates a typical Chinese residential building. The bedroom is selected as the main measurement room, and its size is $5 \mathrm{~m} \times 5 \mathrm{~m} \times 2.7 \mathrm{~m}$.

The tracer gas $\mathrm{SF}_{6}$ was measured by INNOVA 1303 multipoint sampler and a $1412 \mathrm{i}$ analyzer at 70 s intervals. 
In addition, two floor fans are arranged in the bedroom, and the indoor air is stirred before and during the measurement so that the concentration of the tracer gas in each indoor measurement point is as uniform as possible. The specific arrangement is shown in Figure.1. In order to obtain accurate meteorological parameters for the measured building, a small HOBOware Pro weather station was placed on the roof.

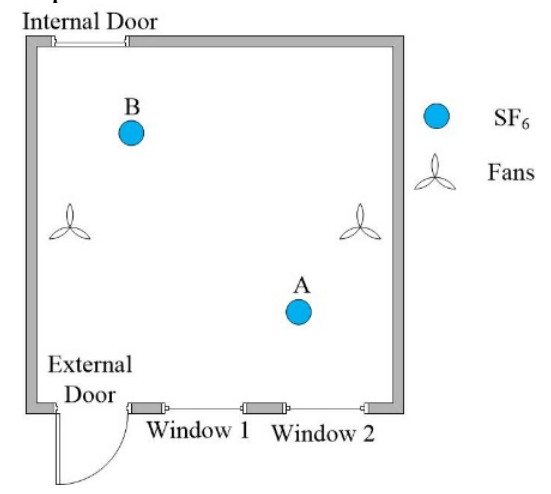

Fig. 1. Measuring point arrangement.

Close the internal, external doors and window 2 during the measurement only operate on the windows 1 . The window size is as shown in Figure.2. The measuring conditions include full opening, $1 / 3(20 \mathrm{~cm})$ opening, $2 \mathrm{~cm}$ opening and infiltration of these four high usage conditions. Measuring Duration is $1.5 \mathrm{~h}$ for full opening and $2 \mathrm{~h}$ for other conditions. Measuring season and date are shown in the Table 1.
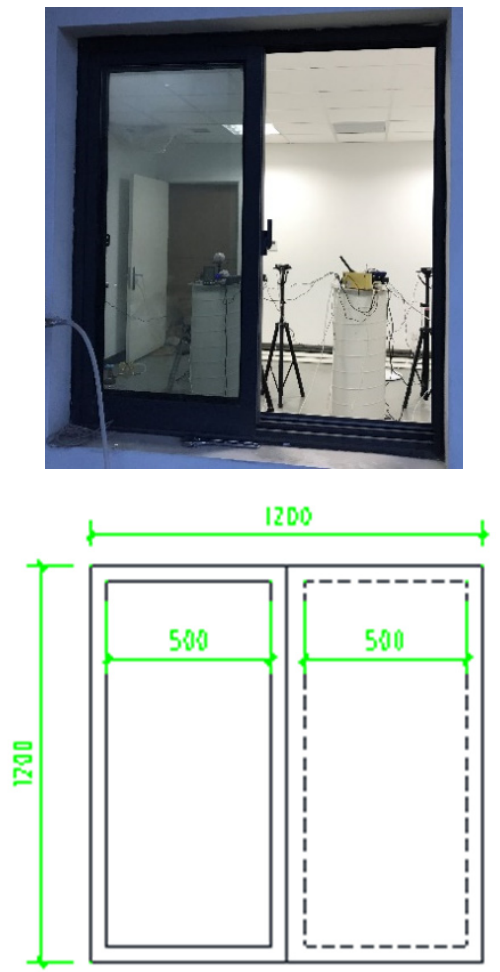

Fig. 2. Bedroom window diagram.

Table 1. Measuring Season and time.

\begin{tabular}{|c|c|}
\hline Measuring Season & Measuring time \\
\hline \multirow{2}{*}{ Spring } & $2017 / 4 / 24 \sim 2017 / 4 / 30$ \\
& $2017 / 5 / 21 \sim 2017 / 5 / 25$ \\
\hline
\end{tabular}

\begin{tabular}{|c|c|}
\hline Plum rain season & $2017 / 6 / 14 \sim 2017 / 6 / 20$ \\
\hline Summer & $2017 / 8 / 24 \sim 2017 / 8 / 30$ \\
\hline Winter & $2018 / 1 / 10-2018 / 1 / 14$ \\
\hline
\end{tabular}

\section{Results and discussion}

Use SketchUp to simplify modeling of the building before EP simulation.

\subsection{EP Single-zone Simulation Results}

The results of a single-zone model calculation without consideration of infiltration are as follows. For the full opening condition, the calculated relative error is $37.40 \%$, the calculated relative error of $1 / 3$ opening is $39.10 \%$ and the calculated relative error of $2 \mathrm{~cm}$ opening is $55.29 \%$. As can be seen from the Figure.4, the calculated results are smaller than the measured results.

Figure.3. shows the statistics of each measuring season for 4 measurement conditions. For full opening, the air change rate is about $1 \sim 3 \mathrm{~h}^{-1}$; for $1 / 3$ opening, the air change rate is about $0.5 \sim 1.3 \mathrm{~h}^{-1}$; for $2 \mathrm{~cm}$ opening, the air change rate is about $0.2 \sim 0.4 \mathrm{~h}^{-1}$; for infiltration, the air change rate is about $0.1 \sim 0.5 \mathrm{~h}^{-1}$. For large openings, the air change rate is relatively large, so the calculated relative error is small. For small openings, the air change rate is relatively small, and the calculated relative error is large.

From the above calculations for the measuring conditions of each season, it can be seen that for this typical residential bedroom, it is necessary to consider infiltration.

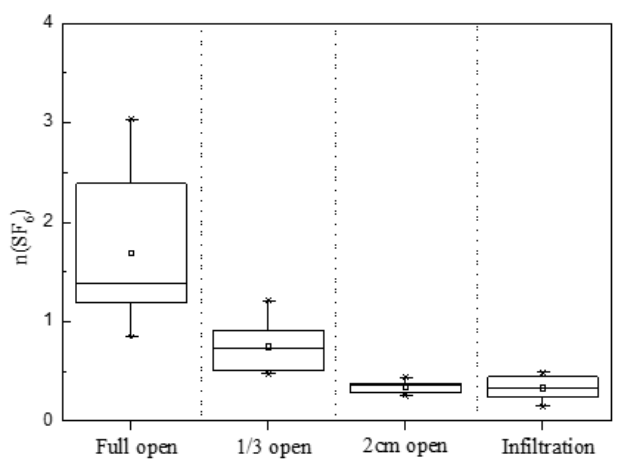

Fig. 3. Air change rate of measuring condition.

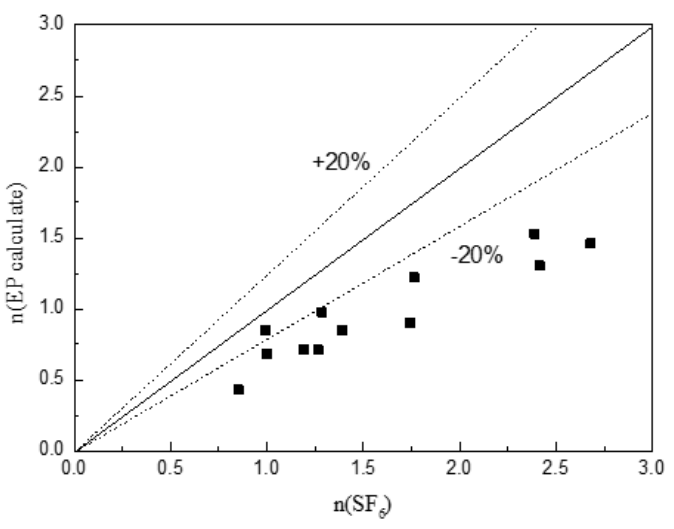

(a) Full opening 


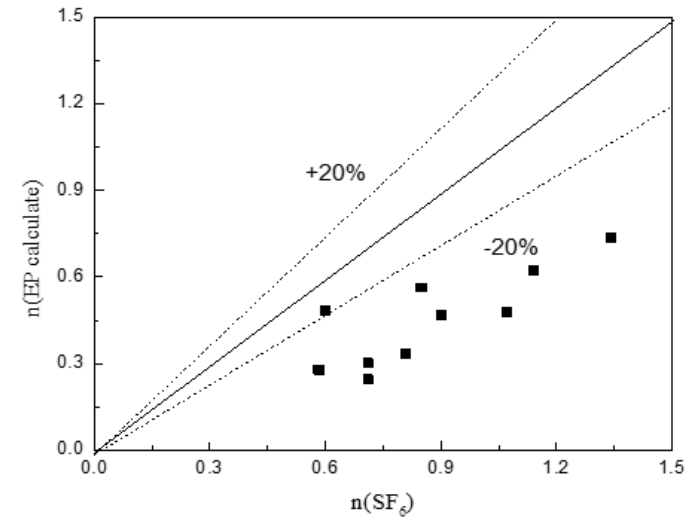

(b) $1 / 3$ opening

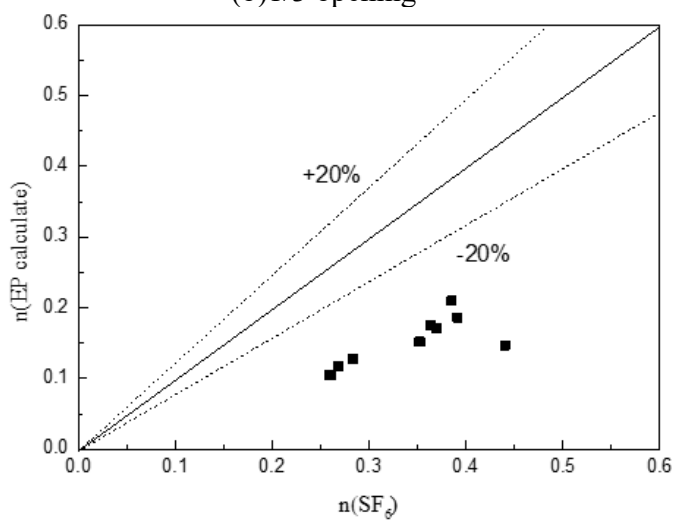

(c) $2 \mathrm{~cm}$ opening

Fig. 4. EP single-zone calculation values of different opening conditions.

\subsection{EP Mutli-zone Simulation Results}

The calculated value of single-zone ventilation is generally less than the measured values and the reason for this phenomenon is the presence of infiltration in the measuring bedroom. There are 4 infiltration sources, internal door, external door, window 1 and window 2 . Through a large number of trial calculations, it has been found that a set of infiltration values cannot meet all of the infiltration conditions, so seasonal difference for infiltration conditions should be considered.

The door and window frame material of the measuring bedroom is all aluminum alloy. Indoor and outdoor temperatures under all conditions are as shown in Figure.5. During the measurement, the minimum indoor temperature is $7.47^{\circ} \mathrm{C}$ and the maximum is $32.4^{\circ} \mathrm{C}$; the minimum outdoor temperature is $3.6^{\circ} \mathrm{C}$ and the maximum is $36.2^{\circ} \mathrm{C}$ under all conditions. It can be seen from the literature[6] that in the range of measured temperature, the thermal expansion coefficient itself does not change significantly and can be ignored. And the thermal expansion coefficient of the aluminum alloy is about $23.2^{*} 10^{-6} \mathrm{~m} /{ }^{\circ} \mathrm{C}$. In the bedroom, the dimensions of the internal and external doors are $2.1 \mathrm{~m} \times 1.2 \mathrm{~m}$ and window 1 , window 2 are $1.2 \mathrm{~m} \times 1.2 \mathrm{~m}$. The total perimeter of the door frame and window frame is $16.2 \mathrm{~m}$.

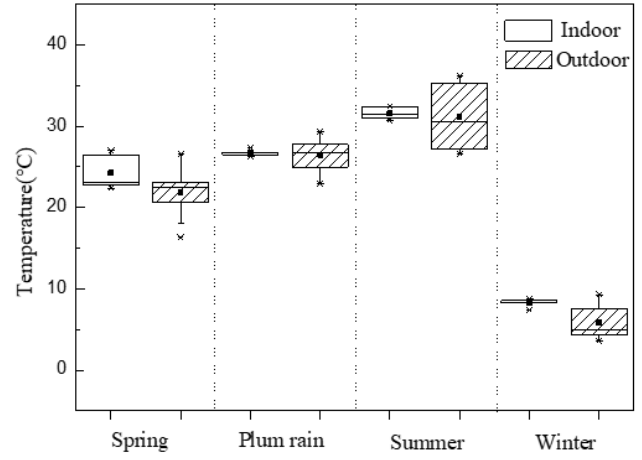

Fig. 5. Temperature of measuring condition

Taking the spring infiltration conditions as a benchmark, it is assumed that the equivalent infiltration area of the external door is $0.013 \mathrm{~m}^{2}$, and the equivalent infiltration area of the internal door and the two external windows is $0.005 \mathrm{~m}^{2}$ each. At this time, the calculation error of the spring infiltration condition is $19.2 \%$. During the measurement, the temperature difference between spring and plum rain season is about $4^{\circ} \mathrm{C}$ and the equivalent infiltration area to the internal door, window1,window2 is $0.005 \mathrm{~m}^{2}$ during the plum rain season. And thus the equivalent infiltration area of the external door is $0.011 \mathrm{~m}^{2}$. Similarly, the temperature difference between spring and summer is about $9^{\circ} \mathrm{C}$, the equivalent infiltration area to the summer of the external door is $0.009 \mathrm{~m}^{2}$; the temperature difference between spring and winter is about $20^{\circ} \mathrm{C}$ and the equivalent infiltration area of the external door is $0.020 \mathrm{~m}^{2}$. Table 2 . shows the above data.

Table 2. Infiltration condition error under different infiltration areas

\begin{tabular}{|c|c|c|c|}
\hline Season & $\begin{array}{c}\text { Inner } \\
\text { door/Window1.2 } \\
\left(\mathrm{m}^{2}\right)\end{array}$ & $\begin{array}{c}\text { Outer } \\
\text { door } \\
\left(\mathrm{m}^{2}\right)\end{array}$ & $\begin{array}{c}\text { Error } \\
(\%)\end{array}$ \\
\hline Spring & 0.005 & 0.013 & 19.2 \\
\hline $\begin{array}{c}\text { Plum rain } \\
\text { season }\end{array}$ & 0.005 & 0.011 & 17.8 \\
\hline Summer & 0.005 & 0.009 & 22.6 \\
\hline Winter & 0.005 & 0.020 & 15.1 \\
\hline
\end{tabular}

Figure. 6 shows the calculated values of all infiltration conditions according to the above infiltration area. The EP average calculation error is $18.17 \%$.

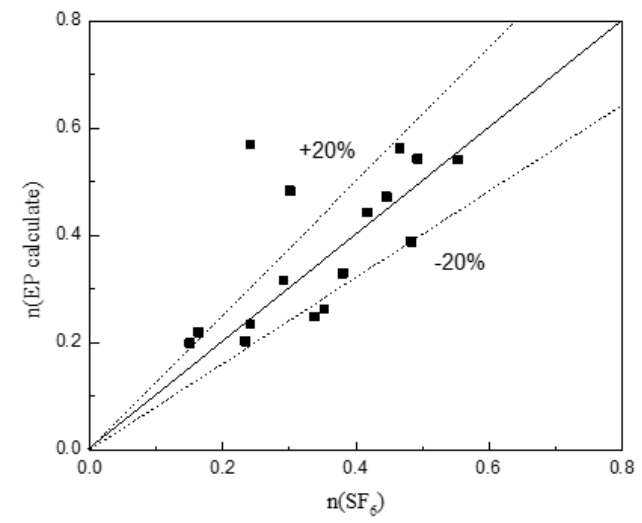

Fig. 6. EP Multi-zone calculation values of infiltration. 
According to the above equivalent infiltration area, the EP calculated error about multi-zone model for full opening, $1 / 3$ opening and $2 \mathrm{~cm}$ opening is $16.02 \%$, $16.74 \%, 28.91 \%$ which are shown in Figure.7.

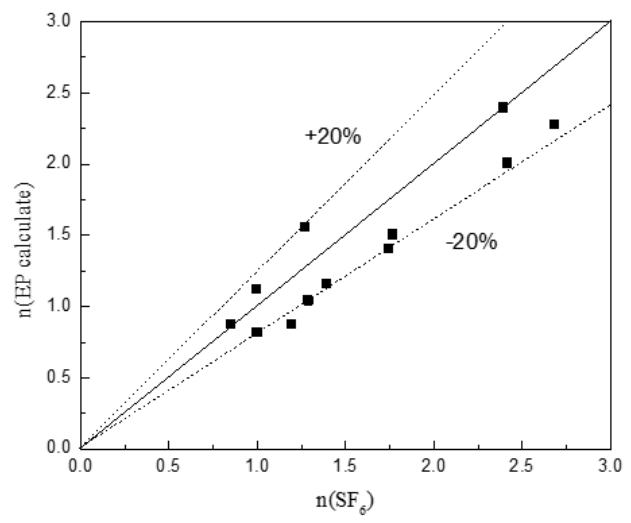

(a) Full opening

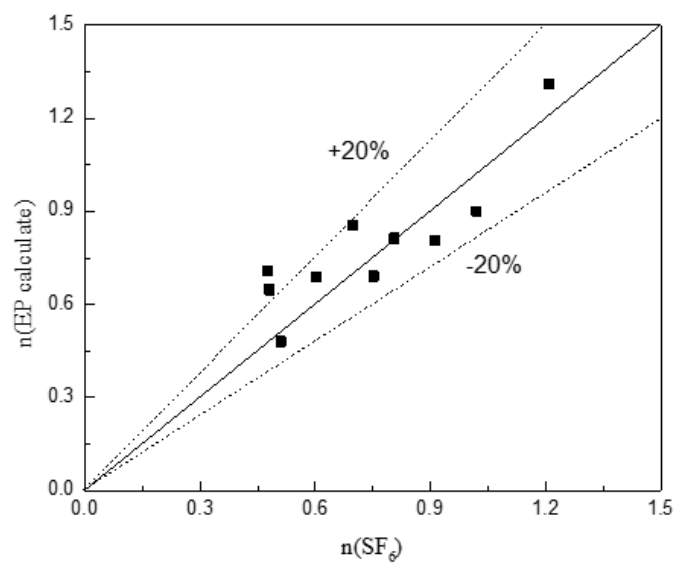

(b) $1 / 3$ opening

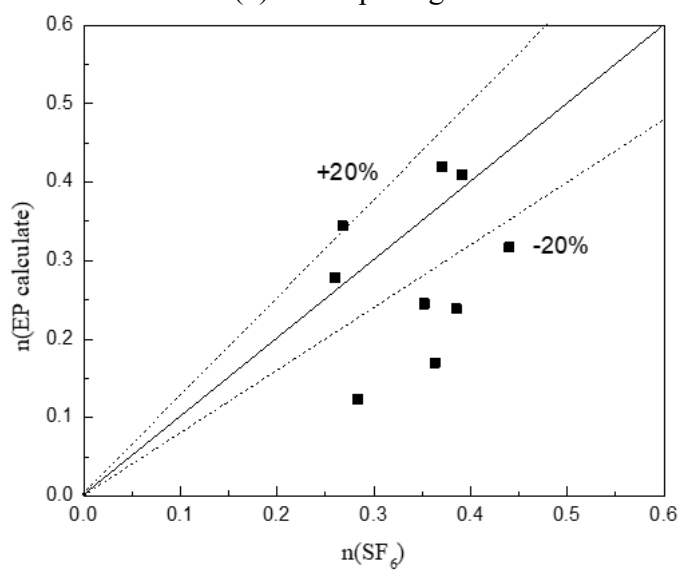

(c) $2 \mathrm{~cm}$ opening.

Fig. 7. EP Multi-zone calculation values of different opening conditions.

And the results of single-zone and multi-zone model are shown in Table 3.

Table 3. EP Single-zone and Multi-zone calculation error.

\begin{tabular}{|c|c|c|}
\hline $\begin{array}{c}\text { Measuring } \\
\text { condition }\end{array}$ & $\begin{array}{c}\text { Single-zone } \\
\text { error }\end{array}$ & $\begin{array}{c}\text { Multi-zone } \\
\text { Error }\end{array}$ \\
\hline Full opening & $37.4 \%$ & $16.0 \%$ \\
\hline $1 / 3$ opening & $39.1 \%$ & $16.7 \%$ \\
\hline $2 \mathrm{~cm}$ opening & $55.3 \%$ & $28.9 \%$ \\
\hline
\end{tabular}

\section{Conclusions}

(1) For residential buildings, it is a common form of ventilation when the doors are closed and the one window is open in modern times, especially during the transition season. Comparing the measured values with the EP calculated values, it is found that the multi-zone model is more suitable for calculating the room air change rate than the single-zone model.

(2) Comparing the measured values with the EP calculated values, it is found that for the infiltration conditions, the temperatures in different seasons are different, and the effective infiltration area will be different due to the existence of the thermal expansion coefficient.

\section{Acknowledgements}

We sincerely appreciate the financial supported by the National Key Research and Development Program of China 2016YFC0700500

\section{References}

1. Huang K., Feng G., Li H., et al. 2014. Opening window issue of residential buildings in winter in north China: A case study in Shenyang. Energy and Buildings, 84: 567-574.

2. Shi S, Chen C, Zhao B. Air Infiltration Rate Distributions of Residences in Beijing $[\mathrm{J}]$. Building \& Environment, 2015, 92:528-537.

3. Meiss A, Feijó-Muñoz J. The energy impact of infiltration: a study on buildings located in north central Spain[J]. Energy Efficiency, 2015, 8(1):51-64.

4. Standard test method for determining air change in a single zone by means of a tracer gas dilution[J]. American Society for Testing \& Materials International Astm Standard E, 2000:1-17.

5. Mathisen H M, Moser A, Nielsen P V. Ventilation effectiveness[J]. 2004.

6. Huang XM, Sun J. Varying rules and mechanism of thermal expansion coefficient for pre-stretched 7050-T7451 aluminum alloy plate[J]. Chinses journal of nonferrous metals. 23(12):3282-328 